\title{
IDENTIFIKASI PENGELOLAAN WAKAF PRODUKTIF PADA PIMPINAN DAERAH MUHAMMADIYAH LUMAJANG 1
}

\author{
Hilda Gita Mayasari \\ Departemen Ekonomi Syariah-Fakultas Ekonomi dan Bisnis-Universitas Airlangga \\ Email: hildagita1515@gmail.com \\ A. Syifa'ul Qulub \\ Departemen Ekonomi Syariah-Fakultas Ekonomi dan Bisnis-Universitas Airlangga \\ Email: a-syifaul-q@feb.unair.ac.id
}

\begin{abstract}
:
This study aims to describe management of productive endowments managed by the Regional Leadership Muhammadiyah Lumajang where in this case a nazhir appointed by the United Muhammadiyah to manage the productive endowments. This research uses descriptive qualitative approach by using case study strategy. Analytical techniques based on theoretical prepositions follow theoretical prepositions that guide case studies. Data validity technique using triangulation technique, that is test the credibility of data that have been obtained by correcting through some technique, like interview, observation, and documentations. The results show that Muhammadiyah Regional Leaders have managed their assets or productively in order to achieve the benefit of Moeslims in Lumajang District. Endowments management conducted by PDM Lumajang is divided into four business charities, namely religion, education, health, social and economic. In the management of productive endowments PDM Lumajang can do several things, namely to perform management functions in the implementation of productive endowments and create jobs for local communities.
\end{abstract}

Keywords: Productive Endowments, Muhammadiyah, Economic Independence.

\section{PENDAHULUAN}

Islam selalu mengajarkan umatnya untuk berbuat baik kepada saudaranya. Dalam konsep Islam, Islam memiliki banyak kegiatan sukarela (tabarru') untuk membantu saudara-saudara yang kurang mampu, yakni wakaf, shadaqah, infaq, hibah yang merupakan beberapa bentuk kegiatan sukarela dalam Islam. Kegiatan sukarela tersebut adalah filantropi Islam. Dalam buku Revitalisasi Islam (Bamualim, 2005:3-5) filantropi merupakan istilah dari bahasa Yunani, philos yang berarti cinta serta praktek memberi (giving), pelayanan (service), dan asosiasi (association) secara sukarela untuk membantu pihak lain yang membutuhkan sebagai ekspresi cinta.

Salah satu kegiatan sukarela dalam Islam yang sudah dipratekkan oleh Nabi Muhammad SAW, walaupun tidak secara eksplisit tercantum dalam AlQur'an adalah wakaf. Dalam sejarah Islam, wakaf berperan penting untuk mendukung pembangunan saranasarana umum. Seperti halnya, masjid, sekolah, rumah sakit, panti asuhan, dan sarana umum lainnya. Di Madinah, Rasulullah SAW membangun Masjid Quba sebagai wakaf pertama, kemudian beliau membangun Masjid Nabawi di atas tanah yang dibelinya dari anak yatim Bani Najjar

\footnotetext{
${ }^{1}$ Jurnal ini merupakan bagian dari skripsi Hilda Gita Mayasar, NIM: 041411431 127, yang diuji pada tanggal 20 Juli 2018.
} 
dengan harga delapan ratus dirham (Qohaf, 2005:6). Hal ini banyak dipahami sebagai wakaf pertama dalam Islam yang kemudian turut diikuti oleh sahabatsahabat yang lain.

Menurut Imam Abu Hanifah, wakaf adalah menahan suatu benda yang menurut hukum tetap menjadi milik si wakif namun manfaatnya dipergunakan untuk kebajikan demi kemaslahatan umat. Sedangkan Imam Malik berpendapat bahwa wakaf tidak melepaskan harta yang diwakafkan dari kepemilikan wakif, namun wakaf justru mencegah wakif melakukan tindakan yang dapat melepaskan kepemilikan atas harta tersebut kepada orang lain dan wakif berkewajiban menyedekahkan manfaatnya serta tidak boleh menarik kembali wakafnya.

Perkembangan wakaf produktif di Indonesia, dari data sampai pertengahan tahun 2017 ini dapat dikatakan sudah baik. Wakaf produktif saat ini bukan menjadi wacana lagi tapi sudah dipraktekkan di berbagai daerah di Indonesia. bahkan beberapa diantaranya sudah menunjukkan kemajuan yang patut dibanggakan dan dapat dicontoh oleh nazhir-nazhir yang lain.

Di Jawa Timur tepatnya di kabupaten Lumajang, nazhir dari Pimpinan Daerah Muhammadiyah kabupaten Lumajang mendirikan SPBU yang sebagian sahamnya dari wakaf dan hasilnya untuk biaya operasional panti asuhan yatim. Berawal modal aset wakaf dan infak dari masyarakat, kemudian mampu berdirilah Panti Asuhan Yatim Piatu Putera Muhammadiyah. Melalui amanah wakaf tersebut, PDM Lumajang terus menerus berupaya untuk mengembangkan amal usahanya mulai dari bidang ekonomi, pendidikan, dan layanan kesehatan untuk masyarakat.

Hingga pada tahun 2007, PDM Lumajang turut membangun SPBU Syirkah Amanah. Kemudian baru diresmikan pada tahun 2009 oleh Ketua Umum PP Muhammadiyah, Prof Din Syamsuddin. SPBU ini dibangun di tanah wakaf seluas $250 \mathrm{~m}^{2}$. Hal ini yang kemudianmembuat SPBU Syirkah Amanah Lumajang menjadi satu-satunya SPBU yang berdiri di atas tanah wakaf. Saat ini pun omzet SPBU Syirkah Amanah Lumajang sudah mencapai 32 ton per hari. Memasukitahun 2017 pun, PDM Lumajang tercatat sudah memiliki prestasi amal usaha yang mencakup berbagai macam pengembangan yakni: 1) Panti Asuhan Yatim Piatu Putera dan Puteri Muhammadiyah; 2) SPBU Syirkah Amanah Lumajang; 3) SMK Muhammadiyah Lumajang; 4) Minimarket Syirkah Amanah, serta amal usaha lainnya.

\section{Rumusan Masalah}

Rumusan masalah dalam penelitian ini adalah Bagaimana Identifikasi pengelolaan aset wakaf produktif pada Pimpinan Daerah Muhammadiyah Lumajang.

\section{Tujuan Penelitian}


Untuk mengidentifikasi dan mengetahui pengelolaan aset wakaf produktif pada Pimpinan Daerah Muhammadiyah Lumajang. Sehingga dapat diketahui apakah PDM Lumajang dapat menjalankan fungsi manajemen wakaf produktif.

\section{LANDASAN TEORI}

Menurut Imam ash-Shan'ani dalam Hafidhudin (2007:158), secara istila (terminologi), wakaf didefinisikan sebagai menahan harta yang mungkin diambil manfaatnya tanpa menghabiskan atau merusak bendanya dan digunakan untuk kebaikan. Sabiq (1987:153) menyatakan bahwa wakaf berarti menahan harta dan memberikan manfaatnya di jalan Allah Swt.

Dahwan (2008:72) menyatakan bahwa hampir dapat dikatakan jika semua benda wakaf merupakan harta produktif dengan arti benda wakaf itu memberikan manfaat. Jika dilihat dari penggunaan manfaat yang dihasilkan tersebut, penggunaan wakaf dibagi menjadi dua. Pertama, wakaf langsung, yaitu wakaf yang pokok barangnya digunakan untuk mencapai tujuannya, seperti masjid untuk sholat, sekolah untuk kegiatan belajar mengajar, rumah sakit untuk mengobati orang sakit dan lain sebagainya. Kedua, wakaf produktif yaitu pokok barangnya digunakan untuk kegiatan produksi dan hasilnya digunakan sesuai dengan tujuan wakaf.

Merupakan sumber dana potensial bagi kepentingan peningkatan kualitas umat, seperti pendidikan, kesehatan, dan kesejahteraan, dan lain sebagainya. Wakaf dapat dikatakan sebagai investasi bisnis dan sosial karena dengan berwakaf seseorang dapat menginvestasikan harta miliknya yang kemudian keuntungan atau manfaat atas harta benda tersebut disalurkan pada kegiatan-kegiatan sosial masyarakat.

$$
\text { Menurut (Husaini, 2012:3) }
$$
menjelaskan definisi manajemen sesuai asal katanya. Secara etimologi kata manajemen berasal dari bahasa latin, yaitu kata manus dan agree yang berarti melakukan. Kata-kata itu digabung menjadi kata kerja managere yang artinya menangani. Managere diterjemahkan dalam bahasa Inggris dalam bentuk kata kerja to manage, dengan kata benda dengan management, dan manager untuk orang yang melakukan kegiatan Manajemen. Akhirnya manajemen diterjemahkan dalam bahasa Indonesia menjadi Manajemen atau pengelolaan. Kata Manajemen jika ditinjau secara bahasa adalah proses atau usaha yang dilakukan untuk mencapai suatu tujuan.

Manajemen pengelolaan wakaf menempati pada posisi paling penting dalam dunia perwakafan. Karena yang paling menentukan benda wakaf itu lebih bermanfaat atau tidak tergantung pada pola pengelolaan. Kalau pengelolaan benda-benda wakaf selama ini hanya dikelola "seadanya" dengan menggunakan "manajemen 
kepercayaan" dan sentralisme kepemimpinan yang mengesampingkan aspek pengawasan, maka dalam pengelolaan wakaf secara modern harus menonjolkan sistem manajemen yang lebih profesional (Direktorat Pemberdayaan Wakaf:2007).

III. METODE PENELITIAN

Pendekatan yang digunakan pada penelitian ini adalah pendekatan kuantitatif dengan menggunakan strategi studi kasus.Untuk mengetahui pengelolaan wakaf produktif pada penelitian ini menggunakan metode identifikasi pengelolaan wakaf produktif analisis kualitatif.Data-data yang diperoleh dari proses wawancara, observasi, dan dokumenakan di analisis dan diolah berdasarkan landasan teori dan literatur yang akan disajikan dalam bentuk Model pengelolaan wakaf produktif.

\section{HASIL PEMBAHASAN}

\section{Konsep Pengelolaan Wakaf Produktif Menggunakan Sistem Bisnis}

Mengenai konsep wakaf produktif dari Pimpinan Daerah Muhammadiyah Lumajang sendiri adalah bahwa wakaf tidak hanya terbatas dalam pengelolaan konvensional saja seperti dibangunnya masjid atau mushola, namun bagaimana mengelola aset wakaf tadi menjadi lebih bermanfaat dan hasilnya dapat dirasakan oleh masyarakat luas khususnya kemaslahatan Umat Islam.

Sebagai contoh wakaf produktif yang berupa SPBU, bahwa tanah wakaf milik Muhammadiyah Lumajang yang awalnya berupa sawah yang masih menganggur hanya menghasilkan 2 juta rupiah per tahun. Beliau juga menjelaskan bahwa ketika tanah tersebut akan ditanami padi juga tidak menghasilkan terlalu banyak. Namun setelah sawah tersebut dibangun SPBU, maka nilai aset dari sawah tersebut naik secara signifikan.

Dalam mengelola wakaf produktif tidak semua modal didapat dari Muhammadiyah baik dari Pimpinan Pusat, Pimpinan Wilayah, atau Pimpinan Daerah. Karena belum menggerakkan wakaf vang, maka Muhammadiyah mengelola wakaf produkti, Muhammadiyah menggunakan sistem bisnis dalam mengelola aset wakafnya untuk menjadi produktif.

Namun hingga saat ini Pimpinan Daerah Muhammadiyah Lumajang belum menggerakkan dan mengembangkan wakaf vang, dikarenakan wakaf uang yang belum familiar di masyarakat, maka untuk meyakinkan masyarakat pun tidak mudah. Oleh karena itu saat ini Muhammadiyah Kabupaten Lumajang lebih memilih wakaf dalam bentuk lain yang lebih dikenal sehingga penghimpunannya lebih mudah.

Hasil Identifikasi Pengelolaan Wakaf
Produktif
Setelah dilakukan wawancara
dengan ketiga informan maka peneliti
mengkonfirmasi ulang mengenai
bagaimana pengelolaan wakaf di
Muhammadiyah Kabupaten Lumajang.


Sehingga, berdasarkan data dapat dijabarkan bagaimana pengelolaan wakaf di Muhamamdiyah Lumajang yang meliputi, proses penghimpunan aset wakaf, pendayagunaan atau pemanfaatan aset wakaf, dan pendistribusian hasil wakaf kepada mauquf alaih.

Menurut Bank Indonesia (2016), dalam penghimpunan aset wakaf nazhir harus mempunyai kebijakan yangkomprehensif mengenai jenis-jenis aset wakaf yang ingin diperoleh.Pemilihan atas aset wakaf yang dihimpun oleh nazhir harus disesuaikan dengan kemampuan nazhir dalam mengelola ase tersebut.

Namun, dalam prakteknya pada nazhir Perserikatan Muhammadiyah yang diwakilkan pada Pimpinan Daerah Muhammadiyah Lumajang, penghimpunan aset wakaf tidak memperhatikan mengenai jenis-jenis aset wakaf yang ingin dihimpun. Oleh karena itu, kebanyakan aset milik Muhamamdiyah Kabupaten Lumajang berupa masjid dan mushola.

Pokok pengaturan pendayagunaan wakaf mengenai bagaimana hal yang spesifik tentang optimalisasi aset wakaf agar berdaya guna dari suatu aset wakaf yang menganggur ataupun aset wakaf yang mendatangkan laba tetapi tidak optimal. Pengaturan harus dapat membuat semacam sanksi apabila nazhir membiarkana set wakafnya menganggur bila tidak ada alasan yang dibenarkan. (Bank Indonesia, 2016).

Pendayagunaan pada aset wakaf milik Muhammadiyah Kabupaten Lumajang telah didayagunakan secara optimal, kebanyakan aset mereka sudah didayagunakan meskipun aset wakaf yang didayagunakan secara produktif masih belum banyak, namun mereka sudah berhasil mendayagunakan aset wakaf mereka secara produktif.

Pokok pengaturan pendistribusian aset wakaf adalah mengenai aturan yang mengharuskan nazhir mempunyai kebijakan mengenai distribusi keuntungan (yang dihasilkan dari waqf project) kepada mauquf alaih. Kebijakan tersebut harus mengakomodasi peruntukan yang telah dijelaskan oleh wakit ketika wakif melakukan ikrar wakaf (Bank Indonesia, 2016).

Untuk pengalokasian hasil wakaf produktif antara lain adalah untuk lembaga-lembaga yang memerlukan terutama untuk panti asuhan dan sisanya untuk pengembangan Muhammadiyah dengan pembagian yang proposional.

Hasil penelitian menunjukkan bahwa Muhammadiyah Kabupaten Lumajang mengelola aset wakaf yang diamankah oleh wakif secara produktif dan konvensional. Pimpinan Daerah Muhammadiyah Lumajang selaku perwakilan nazhir Perserikatan Muhammadiyah dalam mengelola wakaf membaginya menjadi empat bidang amal usaha. Pertama harta wakaf 
digunakan untuk membangun masjid atau mushola. Kedua, harta wakaf digunakan untuk lembaga pendidikan dengan membangun sekolah atau TPA/TPQ. Ketiga, harta wakaf digunakan untuk lembaga kesehatan dengan membangun klinik atau rumah sakit. Keempat, harta wakaf digunakan untuk bidang ekonomi dan sosial. Dalam mendayagunakan harta wakaf di bidang ekonomi dan pendidikan ini Muhammadiyah Kabupaten Lumajang dapat menyerap tenaga kerja sehingga dapat meningkatkan kesejahteraan masyarakat setempat.

Berdasarkan hasil penelitian pada Pimpinan Daerah Muhammadiyah Lumajang dalam mengelola aset wakaf mereka telah menjalankan fungsi manajemen wakaf produktif dan menciptakan lapangan kerja bagi masyarakat setempat melalui wakaf produktif.

\section{SIMPULAN}

Pimpinan

Daerah

Muhammadiyah Lumajang menggalang harta wakaf yang didapatkan dari masyarakat di lingkungan Muhammadiyah ataupun masyarakat yang bukan latar belakang Muhammadiyah di Kabupaten Lumajang. Tanah atau aset wakaf yang mereka miliki didayagunakan ke dalam empat bidang, yaitu bidang agama, pendidikan, kesehatan, sosial dan ekonomi. Dalam bidang agama harta wakaf dikelola untuk masjid atau mushola. Dalam bidang pendidikan dikelola untuk sekolah dan TPA/TPQ. Bidang kesehatan harta wakaf dikelola untuk pembangunan klinik kesehatan dan rumah sakit. Sedangkan dalam bidang sosial dan ekonomi, PDM Lumajang mengelola harta wakafnya dengan membangun panti asuhan dan SPBU serta swalayan.

Tanah wakaf yang dikelola secara produktif oleh Pimpinan Daerah Muhammadiyah Lumajang seperti sekolah, klinik atau rumah sakit, SPBU, dan swalayan telah mampu dikelola secara baik sehingga dapat memberikan pekerjaan kepada masyarakat Kabupaten Lumajang dan dapat menjadi sumber pendapat mereka.

\section{DAFTAR PUSTAKA}

Al Bujairomi, Sulaikman bin Muhammad. 2015. Bujairomi "alaa al khatib. Offline. Maktabah Syamilah.

Al Hasani, Muhammad Ar Rouf Qosimiy. 2007. At Tathwiir At Takhrijiy wa At Tasyri'i li An Nidzomi Al-Waqfi: Numudzujil latishodi At Tazommuniy. Jordan: Chasier du CREAD.

Bamualim, Chaider S dan Irfan Abubakar, 2005. Revitalisasi Filantropi Islam, Studi Kasus Lembaga Zakat dan Wakaf di Indonesia. Pusat Bahasa dan Budaya UIN Syarif Hidayatullah.

Bungin, M. B. 2007. Penelitian Kualitatif. Jakarta: Kencana 
Djunaidi, Achmad. 2006. Menuju Era Wakaf Produktif. Jakarta: Mitra Abadi Press.

Hafidhuddin, Didin. 2007. Agar Harta Berkah dan Bertambah: Gerakan Membudayakan Zakat, Infak, Sedekah, dan Wakaf. Jakarta: Gema Insani Press.

Hasan, Sudirman. 2011. Wakaf Uang: Perspektif Fikih, Hukum Positif, dan Manajemen. Malang: UIN Maliki Press (Anggota IKAPI).

Hashmi, Sherafat Ali. 1987. Management of Waqf: Past and Present, dalam Proceeding of The Seminar: Management and Development of Awqaf Properties. Jeddah: Islamic Research and Training Institute, Islamic Development Bank.

Lubis, Suhrawardi K dkk. 2010. Wakaf dan Pemberdayaan Umat. Jakarta: Sinar Grafika.

Kotler, Philip dan Gary Amstrong. 2007. Dasar-Dasar Pemasaran Edisi Kesembilan Jilid I. Jakarta: PT. Indeks.

M. Manullang. Dasar-Dasar Manajemen. Yogyakarta: Universitas Gadjah Mada.

Mizan, Fitra. 2008. Efektivitas Tabungan Wakaf Indonesia dalam Penghimpunan dan Pendayagunaan Wakaf. Skripsi Tidak Diterbitkan. Jakarta UIN.

Muhammad Abid Abdullah Al-Kabisi. 2004. Hukum Wakaf. Jakarta: IIMAN.
Muljawan, Dadang, dkk. 2016. Wakaf: Pengaturan dan Tata Kelola yang Efektif. Jakarta: Bank Indonesia.

Mulyani. 2013. Pengelolaan Wakaf Produktif di Yayasan Perguruan Tinggi Nahdlatul Ulama' Surakarta. Skripsi Jurusan Syariah Program Studi Ahwal Al-Syakhsyiyyah Sekolah Tinggi Agama Islam Negeri (STAIN) Surakarta.

Nasution, M.N. 2005. Manajemen Mutu Terpadu (Total Quality Management). Ghalia Indonesia, Bogor.

Nazir, Moh. 2003. Metode Penelitian. Ghalia Indonesia.

Pimpinan Pusat Muhammadiyah. 2005. Anggaran Dasar dan Anggaran Rumah Tangga Muhammadiyah. Yogyakarta

Qahaf, Mundzir. 2005. Manajemen Wakaf Produktif. Jakarta: Khalifa.

Rozalinda. 2015. Manajemen Wakaf Produktif. Jakarta: PT Rajagrafindo Persada.

Sabiq, Saddiq. 1987. Fikih Sunnah 14. Bandung: PT Alma'arif.

Sugiyono. 2015. Metode Penelitian Kuantitatif, Kualitatif, dan R\&D. Bandung: Alfabeta.

Wibisono, Yusuf (ed). 2011. Paradigma Baru Pengelolaan Wakaf Untuk Kesejahteraan Bangsa dalam Indonesia Shari'ah Economic Outlook 2011. Jakarta: Lembaga Penerbit FEUI. 
Mayasari, et al/Jurnal Ekonomi Syariah Teori dan Terapan Vol. 6 No. 6 Juni 2019: 1129-1136; IDENTIFIKASI PENGELOLAAN WAKAF PRODUKTIF PADA PIMPINAN DAERAH MUHAMMADIYAH LUMAJANG

Yin, Robert K. 2013. Studi Kasus: Desain dan

Persada.

Metode. Jakarta: PT. Raja Grafindo 